\title{
Matching Food with Mouths: A Statistical Explanation to the Abnormal Decline of Per Capita Food Consumption in Rural China
}

\begin{abstract}
:
This study provides an alternative explanation for the unusual apparent decline in food consumption in rural China after 2000. We find that it is mainly attributable to significant measurement errors in the Chinese Rural Household Survey and the calculation of per capita food consumption. In a household survey, total consumption for a household in a certain period is often well recorded, and per capita consumption is obtained by dividing total consumption by household size. Such a calculation of per capita food consumption is vulnerable to a mismatch between food and mouths. Total consumption may be subject to measurement errors caused primarily by food away from home (FAFH). Also, the household size recorded in the survey is not necessarily the same as the number of mouths (consumption household size), who consume the food recorded in the survey. Our results indicate that per capita food consumption in rural China is currently being underestimated by about $30 \%$. Our results also indicate that income elasticities of food consumption are greater than measured elasticities based on the Rural Household Survey data. A direct policy implication for avoiding statistical errors in calculating per capita consumption would be correctly recording the consumption household size corresponding to total consumption in household surveys.
\end{abstract}

\section{Keywords:}

Food demand, underreporting, rural China, food away from home, off-farm migration

JEL Codes: Q11, C81, O13 


\section{Introduction}

Valid and reliable food and agricultural statistics are essential to the design, implementation, and evaluation of policies related to farmer welfare, consumer welfare, macroeconomic stability, nutritional status, food and agricultural trade, food security, and environmental issues related to agriculture ( $\mathrm{Yu}$ and Abler 2014). In the case of food consumption, Engel's Law predicts that the share of household income spent on food decreases as household income increases, total expenditure on food typically increases. Increases in household income often lead to higher intakes of protein, calories, and micronutrients. However, phenomena that apparently contradict these tendencies have emerged in the food consumption statistics for many developing countries, such as China (Carter, Zhong and Zhu 2012) and India (Deaton and Drèze 2009; Smith 2015), where a declining trend of per capita food consumption and nutrition intake has been observed.

Though the official statistics in China show that both production and imports of food have continuously increased ( $\mathrm{Yu}$ and Zhao 2009), the household surveys in China by the National Bureau of Statistics of China (NBSC) indicate a substantial decline in per capita food grain consumption and a very minor increase in meat and other products both for rural and for urban China since 1990 (Carter, Zhong and Zhu 2012). The Urban Household Survey in China shows that per capita grain consumption dropped from $131 \mathrm{~kg}$ in 1990 to $81 \mathrm{~kg}$ in 2009, while meat consumption only increased from $25 \mathrm{~kg}$ to $35 \mathrm{~kg}$ during the same period for urban China (Zhou, Yu and Herzfeld 2015; Liu et al. 2015; Jiang, Seto and Bai 2015). Similarly, the Rural Household Survey in China, as shown in Table 1, indicates that per capita grain consumption first slightly increased after 1978, then remained steady at about $250 \mathrm{~kg} /$ year until 1997, and then declined to less than $190 \mathrm{~kg} / \mathrm{year}$ in 2009. Rural Household Survey statistics also indicate that per capita vegetable consumption dropped from more than $130 \mathrm{~kg} /$ year before 1990 to less than $100 \mathrm{~kg} / \mathrm{year}$ in 2009, and that per capita meat consumption only increased from $6 \mathrm{~kg} /$ year in 1978 to about $20 \mathrm{~kg} / \mathrm{year}$ in 2009. In terms of 
total caloric intake, the increase in consumption of meat and other products obviously cannot compensate for the apparent decline in grain consumption for both urban and rural China.

Figure 2 shows the changes over time in calorie, protein and fat consumption in rural China in the official statistics by NBSC, indicating that per capita calorie consumption has sharply decreased in recent years, declining from $2605 \mathrm{kcal}$ per day in 2000 to $2266 \mathrm{kcal}$ per day in 2009. The 2009 level of consumption is significantly less than $2780 \mathrm{kcal}$, the dietary energy requirement of a subsistence farmer as calculated by $\mathrm{FAO}^{1}$. There are no official statistics on caloric intake for urban households in China. According to our calculations for urban China, per capita calorie consumption in 1990, 2000 and 2010 was respectively 2150 , 1736, and $1794 \mathrm{kcal}$ per day. This would seem to imply a substantial decline in per capita food consumption in the 1990s in urban China, followed by a period of stability after 2000 . Similar findings are indicated by Carter, Zhong and Zhu (2012, their table 2). These statistics would seem to suggest that the income elasticity of calorie consumption is negative for the past three decades, which is puzzling and contradictory to the findings in the literature (Chen et al. 2015; Shimokawa 2010; Tian and Yu 2013 \& 2015).

On the other hand, statistics on dietary energy consumption for China as whole, as compiled in FAO's Food Balance Sheet (FBS) statistics, show a much different picture. Table 1 reports trends in calorie, protein and fat consumption in China after 1990 calculated from FAO's food balance sheet (FBS) for China. The statistics indicate that dietary energy increased from $2580 \mathrm{kcal}$ per day in 1990-1992 to $2990 \mathrm{kcal}$ per day in 2006-2008, consistent with increasing grain production and net imports in China (Yu and Zhao 2009). In addition, $\mathrm{Wu}$ (2006) finds that the number of overweight and obese people in China has been increasing significantly, which is also consistent with increasing per capita dietary energy consumption.

${ }^{1}$ Source: http://www.fao.org/docrep/003/AA040E/AA040E06.htm\#ch6.1 
What causes the divergence in trends between micro household survey data and macro FBS statistics? Has per capita dietary energy consumption in rural China increased or decreased? It has been known for at least three decades that household survey data for many countries indicate lower levels of per capita food consumption (Dowler and Seo 1985) and higher levels of food insecurity (Barrett 2010) than FBS statistics. There are many possible explanations for this, including (1) food waste and spoilage not reflected in FBS statistics, (2) home production of food not captured by household expenditure surveys, and (3) differences in the types of foods covered on household surveys and in the FBS (Jacobs and Sumner 2002). This paper focuses on a different question, namely, not why levels of per capita food consumption are different between these two data sources but instead why the trends that they indicate for rural China do not agree with each other.

Carter, Zhong and Zhu (2012), and Zhong, Xiang and Zhu (2012) argue that the recent decrease in per capita energy consumption is reasonable in China, and they attribute it to the changing age structure of the Chinese population, specifically to a falling proportion of "big eaters" in the population. We agree that age structure is essential to understanding dietary energy intake. However, this explanation does not solve the contradiction in trends between the household survey and the FBS figures, since both should presumably reflect changes in age structure.

A similar trend of declining per capita food consumption has been observed in India (Rao 2000; Deaton and Drèze 2009; Chattapadhyay and Chowdhury 2010; Patnaik 2010; Basole and Basu 2015; Smith 2015). Rao (2000), and Basole and Basu (2015), suggest that the declining food consumption in India is mainly caused by increasing expenditures on nonfood items, such as fuel, which squeeze food consumption. Deaton and Drèze (2009) suggest that another plausible hypothesis for India is that per capita caloric requirements have fallen due to declining levels of physical activity and possibly also improvements in health, though 
this hypothesis has been criticized by Patnaik (2010). Finally, Chattapadhyay and Chowdhury (2010) and Smith (2015) think that the abnormal decline of food consumption may result from the emergence of new food items (e.g. food items eaten away from home) which are not captured by the food consumption questionnaire. This suggests that the questionnaire should be carefully redesigned.

These explanations could be applied to China as well. However, the statistics for India differ from those for China in that declines in per capita food consumption have been modest in India compared to larger apparent declines in rural China based on household survey data. These explanations also cannot well explain the contradictory trend of the macro increase of food production and imports.

This paper argues that the apparently contradictory statistics for rural China are due to significant measurement errors in the household food survey and the calculation of per capita food consumption. In a household survey, such as the Rural Household Survey in China, total food consumption for a household in a certain period is often well recorded, and per capita consumption is obtained by dividing total consumption by household size. Such a calculation of per capita food consumption is vulnerable to a mismatch between food and mouths. First, total consumption may be subject to measurement errors, caused by (1) guest consumption (consumption by household guests or consumption by household members as guests of other households), and (2) food away from home (FAFH). Second, the household size as measured by the survey is not necessarily the same as the number of mouths (consumption household size), who consume the food recorded in the survey.

For reasons explained in this paper, both types of bias can increase significantly as income increases, particularly for rural China. Food consumption and the corresponding calorie consumption have traditionally been used for the calculation of poverty lines in rural 
China. Biased food consumption statistics could lead to inappropriate poverty-reduction policy. Hence it is important to assess and correct the bias from a policy making perspective.

After analyzing the causes and effects of these measurement errors, this paper proposes a method to calibrate and correct the biases. Measurement errors of the type investigated here may exist in other household food consumption surveys, both in China (both in rural and urban China) and in other countries. The method for correcting biases proposed here could easily be extended to other surveys.

\section{Measurement Errors}

In a household survey, such as the Rural Household Survey in China, total food consumption for a household in during a certain time period (say one year) is well recorded, while per capita consumption is obtained by dividing total consumption by household size:

$$
f_{s}=\frac{F_{s}}{h_{s}}
$$

$f_{s}$ is the per capita consumption for the household; $F_{s}$ and $h_{s}$ respectively denote recorded food consumption and household size for this household. This calculation is vulnerable to a mismatch between food and mouths. During a long survey period, there are factors that can bring about significant measurement errors for both $F_{s}$ and $h_{s}$. In addition to these systematic measurement errors, we assume the non-systematic measurement errors, such as filling out dairies incorrectly, have no significant impact on per capita consumption calculation when the sample size is large.

\section{Food Consumption Bias}

Total household consumption as recorded in a survey may be subject to measurement errors caused by (1) guest consumption (consumption by household guests or consumption by 
household members as guests of other households), and (2) food away from home (FAFH). If the survey period is long enough (for instance one year), consumption by household guests and consumption by household members as guests of other households might roughly offset each other based on a principle of reciprocity, and the first source of error could be neglected. The key problem here is FAFH. Smith (2015) also emphasized the importance of FAFH, though a correction method was not provided.

As incomes increase, households often increase their spending on food away from home (FAFH) in restaurants, cafeterias, food stalls, and other venues (Ma et al. 2006; Bai et al. 2010; Liu et al. 2015; Jiang, Seto, Bai 2015). Even if FAFH expenditure is well-recorded in household surveys, these surveys may not collect data on the quantities of foods consumed away from home, as is the case for the Chinese Rural Household Survey ${ }^{2}$. Due to a lack of price and quantity information, FAFH is often neglected in food demand analyses, such as Fan, Wailes, and Cramer (1995) and Gao, Wailes and Cramer (1996).

Figure 3 shows the changes in the share of FAFH in total food expenditure in rural China. NBSC (National Bureau of Statistics of China) only reports the expenditure on FAFH for the period between 1983 and $1998^{3}$. Luckily, another rural household survey in China conducted by the Research Centre for Rural Economy (RCRE) reports expenditure on FAFH in 1993 and the years after 1995. Figure 3 indicates that the figures from RCRE are systematically greater than those from NBSC. Nevertheless, the NBSC survey shows that the expenditure share on FAFH steadily increases from $1.8 \%$ in 1983 to $5.4 \%$ in 1998; while the

\footnotetext{
${ }^{2}$ The Rural Household Survey in China, which is conducted by the National Bureau of Statistics in China (NBSC), provides facilities (accounting books) for the surveyed households to record their daily household consumption and expenditures (including FAFH) for each day. Hence, we believe the records of FAFH and HCES are basically accurate. Even if there are some measurement errors in the recording practices of households, the errors in mean values, which is our main concern, should be mitigated due to the nature of large sample (more than 60000 households in the Rural Household Survey in China)

${ }^{3}$ FAFH consumption after 1998 is merged into the item 'FAFH consumption and other food expenditure, such as food process fees'.
} 
RCRE survey shows the expenditure share increasing from $7.8 \%$ in 1993 to $18.7 \%$ in 2009 . Thus, both surveys show a similar increasing trend of FAFH in rural China.

In order to make the data comparable for the whole period since 1983, we use the data from both surveys for 1993-1998 to adjust the RCRE data to NBSC data for the years after 1998 by assuming a linear relationship between the NBSC and RCRE data. The results are depicted in Figure 3.

If the quantity of food away from home (FAFH) is not included in a demand analysis, the results will of course be biased. When household income is very low, expenditure on FAFH is very small (for instance the figure was only $1.8 \%$ in 1983), and the bias is also small. However, as income increases, the share of FAFH in total food expenditure increases. At the 2009 level of about 15\%, the bias becomes substantial. Denote the quantity of FAFH for the household as $F_{d}$ and define $\theta \equiv 1+F_{d} / F_{s}$, so that total actual food consumption for the household is

$$
F_{a}=F_{s}+F_{d}=\theta F_{s}
$$

\section{Household Size Bias}

Per capita consumption should be based on the number of mouths (consumption household size), who consume the food recorded in the survey. However, empirical analyses

typically use the household size as recorded in the survey, which can be a source of significant bias if some household members are absent during the survey period, as in the household survey in rural China.

The definition of household size used in a survey is often different from consumption household size (Gödecke and Waibel 2016). For instance, a household member in the Rural Household Survey in China is defined as follows: 
Household members are those who live in the household for more than 6 months in the year, and those who have a strong economic and living connection with the household. Even if a member stays more than 6 months outside of the household, if he/she brings his/her main income back to the household, and is economically connected to the household, this person is still counted as a household member. ${ }^{4}$

This definition of household size emphasizes an income connection on the part of a person to the household, which is not necessarily the same as a person's status as a consumer or nonconsumer in the household.

Due to the economic boom of the past three decades in China, more and more people from farm households spend time working in cities. Off-farm migration has become an important strategy for improving living standards (Wang et al. 2011; Han and Chen 2016), especially for younger members of poor rural households. According to statistics from the NBSC, the share of off-farm employment income in total agricultural household income has increased significantly in China during the past three decades, from $19 \%$ in 1983 to $40 \%$ in 2009. Many off-farm migrants are still economically connected with their households, and hence counted as household members in the Rural Household Survey, but much of their consumption is not at home during the survey period. Consumption away from the home during periods of off-farm employment is not captured by the survey. Another source of bias in household size comes from boarding students, who are still economically connected to the household but do not consume food at home during most of the year because they are away at school.

Let $h_{a}$ denote the actual household consumption size, to distinguish it from $h_{s}$, the household size recorded in the survey. Because $h_{s}>h_{a}$, per capita consumption as measured

\footnotetext{
${ }^{4}$ Source: China Yearbook of Rural Household Survey (2010), p. 393.
} 
by the survey is lower than the actual figure. In order to correct the bias, we should adjust the survey household size to consumption household size,

$$
h_{a}=h_{s} * k
$$

$k \equiv \frac{h_{a}}{h_{s}}<1$ is an adjusting factor.

\section{Total Bias}

Define the total bias as $B \equiv \frac{f_{a}}{f_{s}}-1=\frac{\theta}{k}-1>0$, where $f_{s}$ is the per capita consumption for the household as recorded by the survey and $f_{a}$ is its actual value. We can rewrite the total bias as

$$
B=\left(\frac{1}{k}-1\right)+\frac{\theta-1}{k}
$$

Define $H \equiv \frac{1}{k}-1$ and $D \equiv \frac{\theta-1}{k}$. The total bias can then be decomposed into two parts: the first bias $H$ is due to off-farm migration and/or boarding students, with $H=0$ if there is no bias; and the second bias $D$ is due to food consumed away from home, with $D=0$ in the absence of bias. More off-farm migration or a larger boarding student population (a lower value for $k$ ) increases the magnitude of the FAFH bias $D$ for any given value of $\theta$.

\section{Approximate Corrections for Measurement Errors}

Exact corrections for measurement errors are not possible for rural China because of a lack of data, and indeed if the data were available there would be no measurement errors to begin with. However, approximate corrections can be made for the food consumption and household size biases. 


\section{Food Consumption Bias Correction}

If we are willing to make the assumption that the composition of food consumed away from home is the same as food consumed at home, then we can approximately correct for biases in food and nutrient consumption levels due to $\mathrm{FAFH}^{5}$. In this case, all food products have the same degree of underestimation, i.e., the value of $\theta$ is the same for all foods. Available evidence indicates that the composition of FAFH is different from food eaten at home (Bai et al. 2010); for example, consumers often eat more meat and less grain when dining out than when eating at home. However, the assumption of identical composition is serviceable for an approximate correction to food consumption bias.

Household consumption surveys that include FAFH usually record expenditures rather than quantities. Expenditures on FAFH include not only the cost of the food itself but also costs of capital and labor involved in food preparation and service. If we know the share of food costs in total costs for FAFH venues, which we denote as $\tau$, we have the following equation:

$$
\theta=1+\frac{F_{d}}{F_{s}}=1+\frac{\tau E_{d}}{E-E_{d}}=1+\frac{\tau\left(E_{d} / E\right)}{1-\left(E_{d} / E\right)}
$$

$E$ and $E_{d}$ are total food expenditure and FAFH expenditure, respectively, and $E_{d} / E$ is the share of expenditure on FAFH in total food expenditure.

The Statistical Yearbook of China: Chain Stores of Retail Trades and Catering Services, published by NBSC, reports the share of material costs in total revenue for largescale chain restaurants in China, which can serve as a proxy for $\tau$. Table 2 reports the statistics for 2004-2009, and they indicate that the share is relatively stable over time. We use the average value for $2004-2009$ of 0.37 for $\tau$ in our calculations. Because it is possible that

\footnotetext{
${ }^{5}$ It is a strong assumption for Chinese rural households. Liu et al. (2016) find that food-away-from-home has different consumption structure from home consumption in urban China. As we have no detailed food consumption structure for FAFH of Chinese rural households, we however make the assumption in order for simplification. Our sensitive analysis also indicates that this assumption has no substantial impact on our conclusion, as the major bias comes from off-farm employment.
} 
$\tau$ values may vary between different years, we also conducted a sensitivity analysis for different $\tau$ values ( $\tau=0.2,0.3,0.4$ and 0.5 ) in the later analysis as a robustness check.

\section{Household Size Bias Correction}

Our correction for household size bias involves an indirect approximation of the adjusting factor $k$. Divide the survey household members $h_{s}$ into those who are in the labor force ( $L$ ), boarding students $(R)$, and everyone else $(U)^{6}$ :

$$
h_{s}=L+R+U
$$

Since migration to cities in China is overwhelmingly composed of those who are in the labor force, we assume as an approximation that all of the food consumption by those who are not in the labor force and not away at boarding school is captured by the household survey. Food consumption by labor force members is captured by the survey during those times of the year that they are working on the farm, and not when they are working off the farm. Boarding students only eat at home during school breaks, which are about 3 months in China (two months for summer break and one month for winter break). Then

$$
k=\frac{\rho L+0.25 R+U}{h_{s}}
$$

$\rho$ denotes the proportion of time spent on the farm for those in the labor force during the survey period.

Lu (2012) reviews trends in migrant workers' monthly wages for China $\left(w_{0}\right)$. As the Rural Household Survey reports annual farm income $\left(y_{A}\right)$ and annual off-farm income $\left(y_{o}\right)$,

\footnotetext{
${ }^{6}$ The Rural Household Survey of China reports the number of students in total and the number of students aged 7-15 per household after 2002. In China, children usually start primary school at 7 and enter high school or vocational school at 16, which is when most students start boarding. The gap between the two numbers is a good approximation for the number of boarding students. The statistics show that the number of students over 16 per household is relatively stable, ranging between 0.2 and 0.3 after 2002, and the mean is 0.27 .
} 
we can estimate off-farm work time for those in the labor force by diving off-farm income by the wage level, so that

$$
\rho=1-\frac{\left(y_{o} / 12\right)}{w_{0}}
$$

\section{Impacts of Measurement Errors on Food Demand Elasticities}

We can assess whether measurement errors cause estimated food demand elasticities using survey data to be different from elasticities that would be obtained if food consumption and household size were measured correctly. First, we examine income elasticities. The income elasticity using survey data is $\eta_{s}=\partial \ln f_{s} / \partial \ln y$, whereas the actual income elasticity is $\eta_{a}=\partial \ln f_{a} / \partial \ln y$. Because $f_{a}=(\theta / k) f_{s}$, differences between measured and actual income elasticities depend on how $\theta$ and $k$ change as income increases:

$$
\eta_{a}=\frac{\partial \ln \theta}{\partial \ln y}-\frac{\partial \ln k}{\partial \ln y}+\eta_{s}
$$

Income is typically positively correlated with the proportion of total food consumption that is eaten away from home, so that $\partial \ln \theta / \partial \ln y>0$. Income is also typically negatively correlated with the share of farm work time in total work time, at least as long as the source of the increase in income is not coming from farm operations, so that $\partial \ln k / \partial \ln y<0$. This implies that increases in income raise the ratio $\theta / k$, so that actual income elasticities of demand for food products are larger than elasticities obtained using survey data.

Second, we examine price elasticities. The price elasticity using survey data for a food product is $\varepsilon_{s}=\partial \ln f_{s} / \partial \ln p$ whereas the actual price elasticity is $\varepsilon_{a}=\partial \ln f_{a} / \partial \ln p$, with

$$
\varepsilon_{a}=\frac{\partial \ln \theta}{\partial \ln p}-\frac{\partial \ln k}{\partial \ln p}+\varepsilon_{s}
$$


If a food product is not being produced by the household, and if its market price is not correlated with market prices of food products that the household does produce, then there is no particular reason to expect a change in its price to have a significant impact on either $\theta$ or $k$. In this case, we can conclude that measurement errors have only a minimal impact on price elasticities.

On the other hand, if a food item is produced by the household, or its market price is correlated with market prices of food items that the household does produce, then a change in the price of that product will affect both household income and the incentives of household members to work on the farm, points emphasized in the agricultural household models literature (Taylor and Adelman 2003). Higher prices in this case mean higher household incomes $(\partial \ln y / \partial \ln p>0)$ and a greater proportion of food consumed away from home $(\partial \ln \theta / \partial \ln y>0)$. Higher prices also create incentives to reallocate time away from off-farm work and toward farm work $(\partial \ln k / \partial \ln p>0)$. The net impact of these changes on the ratio $\theta / k$, and in turn on the difference between $\varepsilon_{s}$ and $\varepsilon_{a}$, is ambiguous.

\section{Application to the Chinese Rural Household Survey}

Using the methodology outlined here, we can derive approximate corrections for per capita food consumption of rural households of China. The main variables and the estimated biases in the Rural Household Survey data are reported in Table 3. The figures in Table 3 indicate that the bias in per capita food consumption has steadily increased as per capita income has increased. Corrected per capita consumption for 1983 is only $12 \%$ higher than the reported number from the NBSC, of which 11 percentage points are due to migration and boarding students, and 1 percentage point to FAFH. However, the bias increases to $29 \%$ in 2009 , of which 21 percentage points is due to migration and boarding students, and 8 
percentage points to FAFH. The bias is greater than $20 \%$ for every year after 1999 and the recent bias is close to $30 \%$, which is a very large number.

We also conducted a sensitivity analysis for different values of $\tau$, the share of food costs in total costs for FAFH venues. It is reported in Table 4. We find that different $\tau$ values do not have a substantial impact on our results. This is mainly because the share of FAFH is relatively small in rural China.

The estimated bias can be used for correcting statistics on dietary energy consumption. Figure 4 shows trends in per capita calorie consumption of rural households in China both for the original NBSC data and the data after our corrections. The two lines clearly diverge. Figure 4 also indicates that the corrected per capita energy consumption for rural households in China has been relatively stable in recent years.

Table 5 compares the corrected dietary energy consumption statistics for rural China with corresponding statistics for selected developed and emerging economies. After correction, per capita caloric consumption in 2006-2008 reached 3012 kcal per day, which is only slightly higher than $2990 \mathrm{kcal}$, the national average level for China from FAO. This figure is plausible because rural workers often engage in heavy manual labor whether they are working on or off the farm, and they need more calories than the national average.

After adjusting, we find that per capita calorie consumption in rural China is higher than in the national average for India, slightly lower than in Brazil, and substantially lower than in Russia, the United States, and Germany.

Underreporting of consumption also could significantly bias income and price elasticities, and these biases can be corrected using equations (9) and (10). That is, we need to calculate $\partial \ln (\theta / k) / \partial \ln y$ and $\partial \ln (\theta / k) / \partial \ln p$. Using a simple OLS model and 1983-2009 annual data, we obtain the following relationship (standard errors in parentheses): ${ }^{7}$

\footnotetext{
${ }^{7}$ Food prices are measured by the ratio of the food consumer price index (CPI) to the general CPI.
} 


$$
\begin{aligned}
\ln \left(\theta_{t} / k_{t}\right)= & -0.36+0.16 \ln y_{t}-0.11 \ln p_{t} \\
& (0.19)(0.01)
\end{aligned}
$$

These results provide an estimate for $\partial \ln (\theta / k) / \partial \ln y$ of 0.16 , and this estimate is statistically significant at the $1 \%$ level. This suggests that income elasticities of demand for food products in rural China are, on the whole, underestimated by about 0.16 . Even with an income elasticity of demand as large as one, this is a significant bias of $16 \%$. At an income elasticity of 0.5 , which is more plausible for food products as a whole in present-day rural China (Abler 2010), the bias is over 30\%. In contrast, the estimate of $\partial \ln (\theta / k) / \partial \ln p$ from this equation is not statistically significant at the $5 \%$ level.

\section{Conclusions}

Statistics from the Chinese Rural Household Survey indicate that per capita grain consumption in rural China slightly increased after 1978, then remained steady at about 250 $\mathrm{kg} /$ year until 1997, and then declined to less than $190 \mathrm{~kg} / \mathrm{year}$ in 2009. Rural Household Survey statistics also indicate that per capita vegetable consumption dropped from more than $130 \mathrm{~kg} /$ year before 1990 to less than $100 \mathrm{~kg} / \mathrm{year}$ in 2009, and that per capita meat consumption only increased from $6 \mathrm{~kg} /$ year in 1978 to about $20 \mathrm{~kg} /$ year in 2009. On the other hand, statistics on dietary energy consumption for China as whole, as compiled by FAO, show a much different picture.

This paper argues that these contradictory statistics are due to significant measurement errors in the Rural Household Survey and the calculation of per capita food consumption. In a household survey such as the Rural Household Survey in China, total consumption for a household in a certain period is often well recorded, and per capita consumption is obtained by dividing total consumption by household size. Such a calculation of per capita food consumption is vulnerable to a mismatch between food and mouths. First, 
total consumption may be subject to measurement errors, caused primarily by food away from home (FAFH). Second, the household size recorded in the survey is not necessarily the same as the number of mouths (consumption household size), who consume the food recorded in the survey.

This paper develops a methodology for estimating the magnitudes of the biases in per capita consumption resulting from these measurement errors, and for correcting these biases. This paper also develops a methodology for estimating how income and price elasticities of demand for food products may be biased as a result of these measurement errors.

We find that actual per capita food consumption in rural China is being underreported by about $30 \%$ in the Rural Household Survey, and that this bias has increased significantly over time. The results indicate that calorie consumption in Rural China has remained stable during the past decade, rather than exhibiting a declining trend as reported by NBSC. We also find that the measurement errors lead to an underestimation of income elasticities of demand for food products in rural China by about 0.16 . At an income elasticity of 0.5 , which is plausible for food products as a whole in present-day rural China, this bias is $30 \%$, which is substantial.

Measurement errors of the type investigated here may exist in other household food consumption surveys, both in China and in other countries. The method for correcting biases proposed here could easily be extended to other surveys.

As a policy implication, in order to obtain correct food consumption information for better policy making, questionnaires on household food consumption should take into account (1) the difference between survey household size (usually those who stay more than 6 months in the family in the year) and consumption household size, and (2) food-awayfrom-home consumption and guest consumption. As indicated in the paper, these are the two main sources of statistical errors for China and other developing countries as well. Correct 
per capita consumption should be obtained by dividing correctly recorded total consumption by corresponding consumption household size. 


\section{References}

Abler, D. (2010): Demand Growth in Developing Countries, TAD/CA/APM/CFS/MD(2010)9. Paris: OECD.

Bai, J., T.I. Wahl, B.T. Lohmar, and J. Huang (2010): "Food Away from Home in Beijing: Effects of Wealth, Time and 'Free' Meals," China Economic Review, 21:432-441.

Barrett, C.B. (2010): "Measuring Food Insecurity," Science, February 12, 2010, 327(5967): $825-828$.

Basole A. and D. Basu (2015) Fuelling Calorie Intake Decline: Household-Level Evidence from Rural India. World Development. Vol. 68:82-95.

Carter, C.A., F. Zhong, and J. Zhu (2012): "Advances in Chinese Agriculture and Its Global Implications," Applied Economic Perspectives and Policy, 34(1):1-36.

Chattapadhyay, G., and Chowdhury, A.K. (2010) Trends in Food Insecurity in India: Review of Food Insecurity Assessment and Trends in India and Provinces. Analysis of India Consumer Expenditure Surveys 1988-2005, draft report, Rome: Food and Agriculture Organization of the United Nations.

Chen D., D. Abler, D. Zhou, X. Yu, and W. Thompson (2015), A Meta-Analysis of Food Demand Elasticities for China, Forthcoming in Applied Economics Perspectives and Policy. doi: 10.1093/aepp/ppv006

Deaton, A., and J. Drèze (2009): "Food and Nutrition in India: Facts and Interpretations," Economic and Political Weekly, February 14, 2009, 44(7):42-65.

Dowler, E.A., and Y.O. Seo (1985): "Estimates of Food Supply $v$ Measurement of Food Consumption," Food Policy, 10(3): 278-288.

Fan, S., E.J. Wailes, and G.L. Cramer (1995): "Household Demand in Rural China: A TwoStage LES-AIDS Model," American Journal of Agricultural Economics, 77(1):54-62.

Gödecke T. and H. Waibel (2016): Does the underlying definition of household impair programme targeting?, Journal of Development Effectiveness, Vol. 8(1):87-104

Gao, X.M., E.J. Wailes, and G.L. Cramer. (1996): “A Two-Stage Rural Household Demand Analysis: Microdata Evidence from Jiangsu Province, China," American Journal of Agricultural Economics, 78(3):604-613.

Han X. , and Y. Chen . (2016): Food consumption of outgoing rural migrant workers in urban area of China. China Agricultural Economic Review 8:2, 230 - 249.

Jacobs, K., and D.A. Sumner (2002): "The Food Balance Sheets of the Food and Agriculture Organization: A Review of Potential Ways to Broaden the Appropriate Uses of the Data," Review Sponsored by FAO, ftp://ksph.kz/Chemistry_Food\%20Safety/TotalDietStudies/FBS_Rev.pdf. 
Jiang L., Karen C. Seto, and J. Bai , (2015) "Urban economic development, changes in food consumption patterns and land requirements for food production in China", China Agricultural Economic Review, Vol. 7 Iss: 2, pp.240 - 261.

Liu H. et al.(2015) Household Composition, Income, and Food-Away-From-Home Expenditure in Urban China, Food Policy, Vol.(51):97-103.

Lu, F. (2012): "Wage Trends among Chinese Migrant Workers: 1979-2010" (in Chinese), Chinese Social Sciences (zhong guo she hui ke xue), 2012(7):47-67.

Ma, H., J. Huang, F. Fuller, and S. Rozelle (2006): "Getting Rich and Eating Out: Consumption of Food Away from Home in Urban China," Canadian Journal of Agricultural Economics, 54(1):101-119.

Meng, X., X. Gong, and Y. Wang (2009): "Impact of Income Growth and Economic Reform on Nutrition Availability in Urban China: 1986-2000," Economic Development and Cultural Change, 57(2):261-295.

Patnaik U. (2010) A Critical Look at Some Propositions on Consumption and Poverty. Economic and Political Weekly. Vol. 45(6):74-80.

Rao, C.H.H. (2000) Declining Demand for Foodgrains in Rural India: Causes and Implications. Economic and Political Weekly. Vol. 35(4): 201-206

Shimokawa, S. (2010): "Asymmetric Intra-household Allocation of Calories in China," American Journal of Agricultural Economics, 92(3):873-888.

Smith, L. (2015) The Great Indian calorie Debate: Explaining Rising Undernourishment during India's Rapid Economic Growth. Food Policy. Vol. 50:53-67.

Taylor, J.E., and I. Adelman (2003): “Agricultural Household Models: Genesis, Evolution, and Extensions," Review of Economics of the Household, 1(1):33-58.

Tian, X., and X. Yu (2013): "The Demand for Nutrients in China," Frontiers of Economics in China, Vol. 8(2): 186-206.

Tian, X. and X. Yu (2015) "Using semiparametric models to study nutrition improvement and dietary change with different indices: The case of China", Food Policy, Vol. 53:67-81.

Wang, X., J. Huang, L. Zhang, and S. Rozelle (2011): "The Rise of Migration and the Fall of Self Employment in Rural China's Labor Market." China Economic Review, 22(4):573-584.

Wu, Y. (2006): "Overweight and Obesity in China." British Medical Journal, 333(7564):362-363, doi:10.1136/bmj.333.7564.362.

Yu, X., and D. Abler (2014): "Where Have All the Pigs Gone? Inconsistencies in Pork Statistics in China." China Economic Review, 30:469-484. 
Yu, X., and G. Zhao (2009): "Chinese Agricultural Development in 30 Years: A Literature Review.” Frontiers of Economics in China, 4(4):633-648.

Zhong, F., J. Xiang, and J. Zhu (2012): "Impact of Demographic Dynamics on Food Consumption-A Case Study of Energy Intake in China," China Economic Review,

Zhou D. , X. Yu and T. Herzfeld (2015).'Dynamic Food Demand in Urban China”. China Agricultural Economic Review. Vol. 7(1), pp.27 - 44 

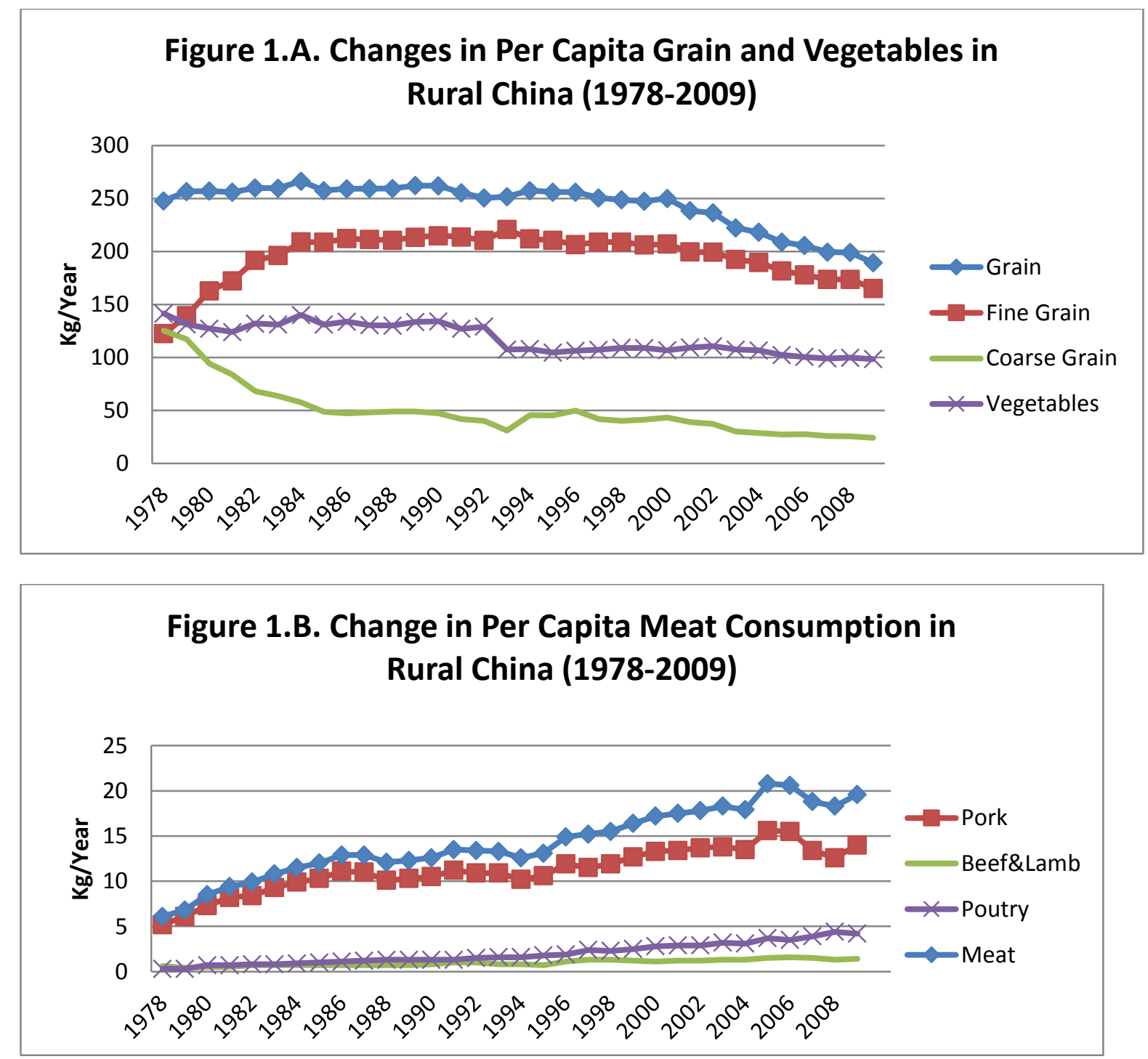

Source: China Yearbook of Rural Household Survey (various years) 


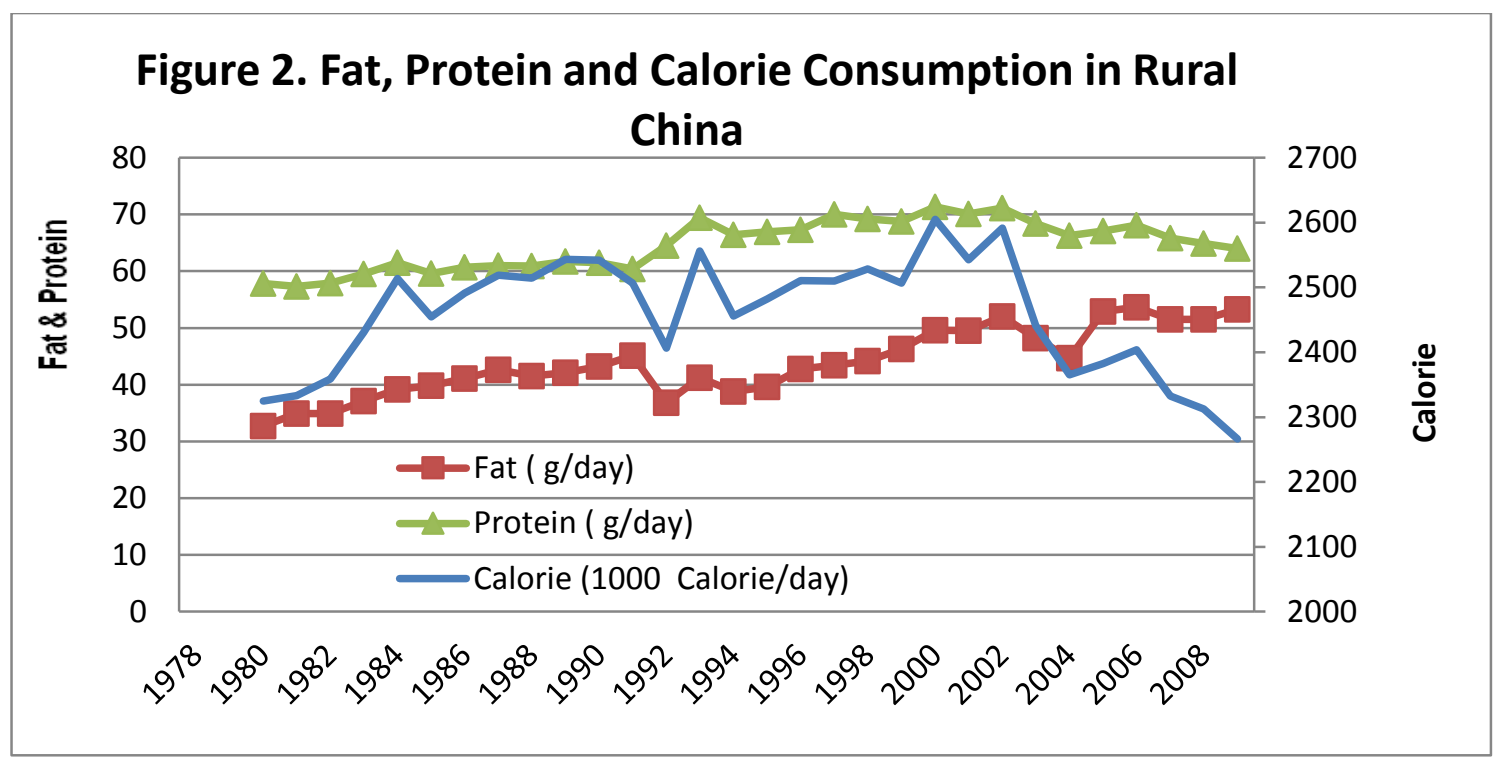

Source: Table 2-27, China Yearbook of Rural Household Survey (2010) 


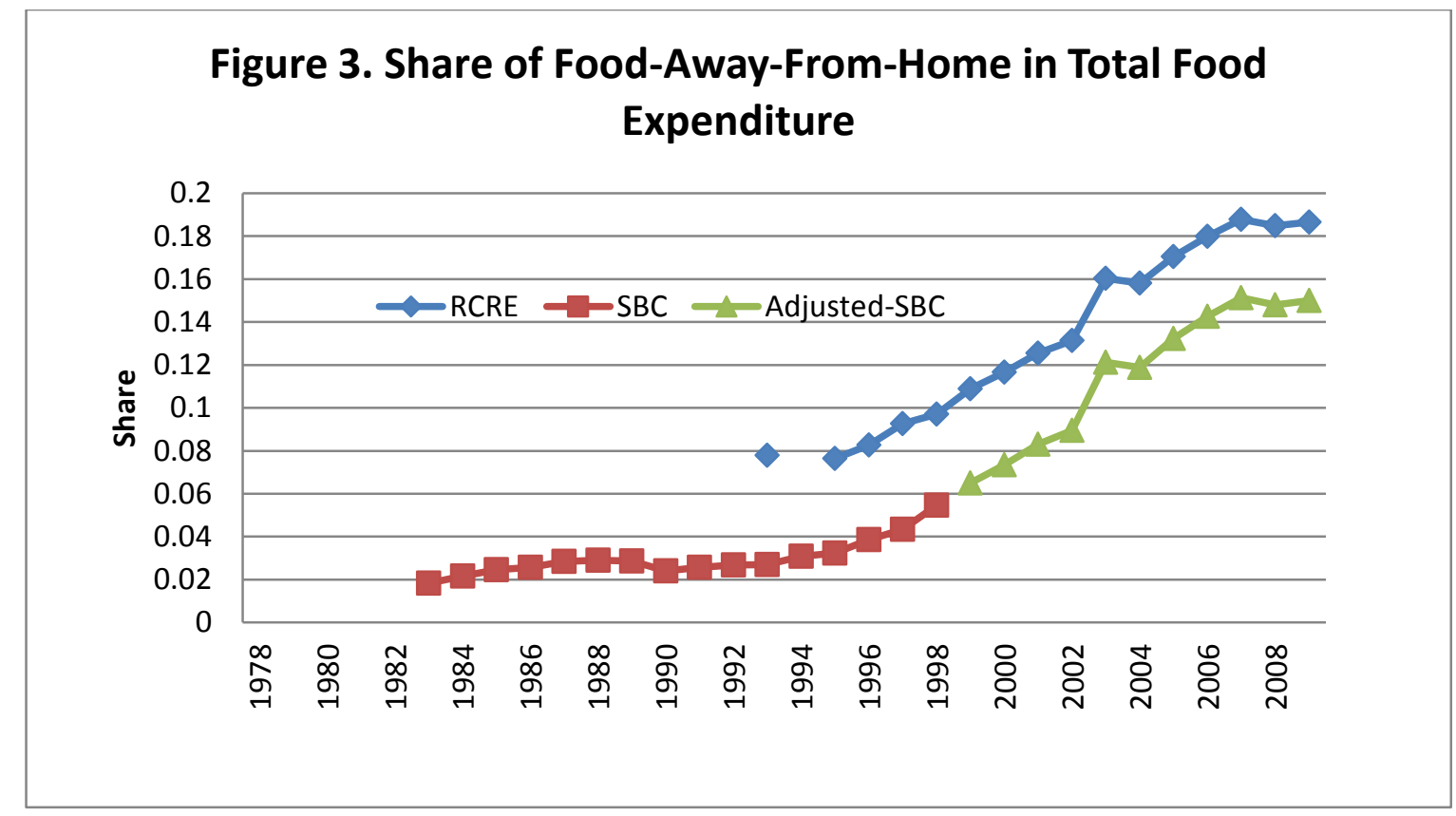

Source: The National Bureau of Statistics of China (NBSC) and the Research Centre for Rural Economy (RCRE).

Notes: NBSC only reports expenditures on food away from home for the period between 1983 and 1998. The survey by RCRE reports the data in 1993 and the years after 1995. Clearly, the figures from RCRE are systematically higher than those from NBSC. We use the data between 1993 and 1998 to adjust the data from RCRE to NBSC data for the year after 1998, by assuming a linear relationship between the data of NBSC and RCRE. 


\section{Figure 4. Calorie Consumption in Rural China}

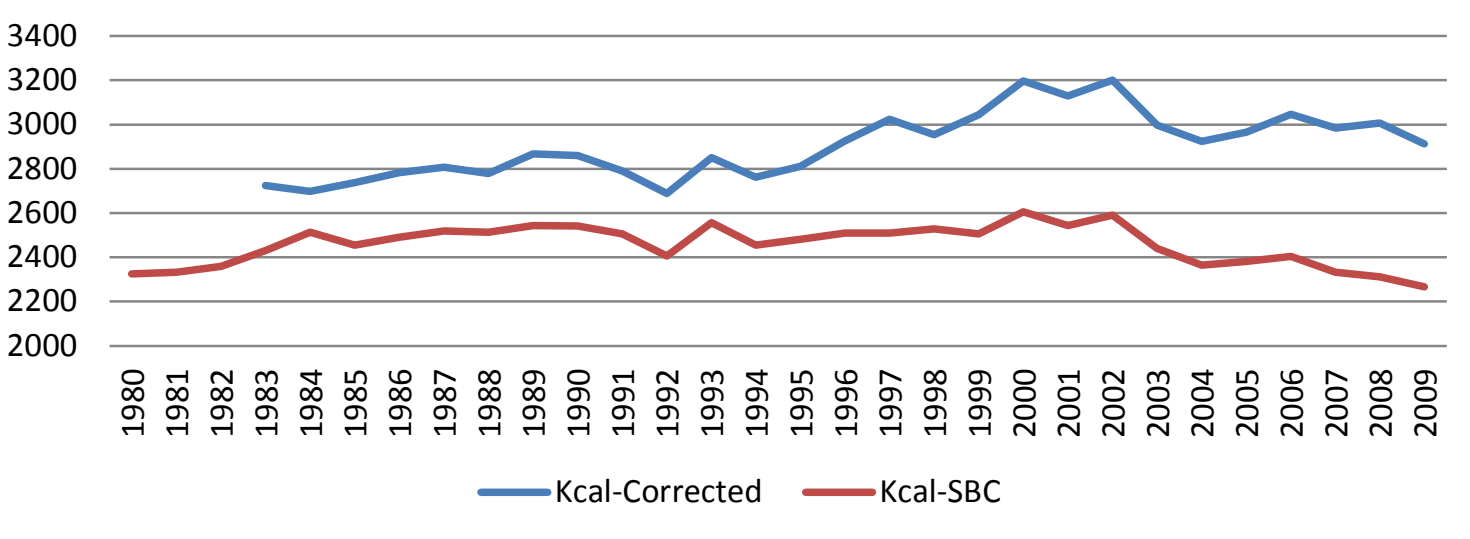


Table 1. Nutrient Consumption in China and Rural China

\begin{tabular}{llllll}
\hline Year & & $1990-92$ & $1995-97$ & $2000-02$ & $2006-08$ \\
\hline \multirow{2}{*}{ Energy(1000 Calories) } & China (FAO) & 2580 & 2840 & 2920 & 2990 \\
& Rural China (NBSC) & 2485 & 2501 & 2580 & 2350 \\
\hline \multirow{2}{*}{ Protein (g/day) } & China (FAO) & 67 & 81 & 86 & 89 \\
& Rural China (NBSC) & 62 & 68 & 71 & 66 \\
\hline \multirow{2}{*}{ Fat (g/day) } & China (FAO) & 58 & 72 & 82 & 90 \\
& Rural China (NBSC) & 49 & 50 & 66 & 75 \\
\hline
\end{tabular}

Sources: FAO \& China Yearbook of Rural Household Survey (2010)

Notes:

1. The data for China as a whole are from the food balance sheet for China in the FAOSTAT database.

2. The data for rural China are from the Rural Household Survey as reported in the China Yearbook of Rural Household Survey (2010). 
Table 2. Revenue and Material Costs for Large-Scale Chain Restaurants

\begin{tabular}{|l|l|l|l|l|l|l|l|}
\hline \multicolumn{2}{|l|}{ Year } & 2004 & 2005 & 2006 & 2007 & 2008 & 2009 \\
\hline Total Revenue & $\begin{array}{l}\text { Billion } \\
\text { Yuan }\end{array}$ & 34.82 & 38.89 & 55.19 & 64.47 & 80.69 & 87.93 \\
\hline $\begin{array}{l}\text { Material Costs } \\
\text { Yuan }\end{array}$ & 12.46 & 14.33 & 20.12 & 23.45 & 27.16 & 36.20 \\
\hline $\begin{array}{l}\text { Material Costs/Total } \\
\text { Revenue }\end{array}$ & & 0.36 & 0.37 & 0.36 & 0.36 & 0.34 & 0.41 \\
\hline
\end{tabular}

Sources: Statistical Yearbook of China Chain Stores of Retail Trades and Catering Services (various editions) 
Table 3. Estimation of Bias in Food Consumption in Rural China

\begin{tabular}{|c|c|c|c|c|c|c|c|c|c|c|c|}
\hline \multirow{2}{*}{ Year } & \multicolumn{3}{|c|}{ Income (Yuan) } & \multirow{2}{*}{$\begin{array}{l}\text { Off-Farm Wage } \\
\text { (Yuan/ Month) }\end{array}$} & \multirow{2}{*}{$\frac{\text { CPI-Rural }}{(1985=100)}$} & \multicolumn{2}{|c|}{$\begin{array}{l}\text { Household Size } \\
\text { and Labor Forces }\end{array}$} & \multirow{2}{*}{$\begin{array}{l}\text { Students } \\
\text { aged } 16 \\
\text { or older }\end{array}$} & \multirow{2}{*}{$\begin{array}{l}\text { Bias } \\
\text { Total } \\
\text { Bias }\end{array}$} & \multirow[b]{2}{*}{$\begin{array}{l}\text { Bias- } \\
\mathrm{H}\end{array}$} & \multirow[b]{2}{*}{$\begin{array}{l}\text { Bias- } \\
\text { D }\end{array}$} \\
\hline & Total & Off-Farm & Farm & & & $\begin{array}{l}\text { Household } \\
\text { Size }\end{array}$ & $\begin{array}{l}\text { Labor } \\
\text { Forces }\end{array}$ & & & & \\
\hline 1983 & 309.8 & 57.5 & 227.7 & 75.0 & 87.0 & 5.4 & 2.8 & & 0.12 & 0.11 & 0.01 \\
\hline 1984 & 355.3 & 66.5 & 261.7 & 240.0 & 89.3 & 5.4 & 2.9 & & 0.07 & 0.06 & 0.01 \\
\hline 1985 & 397.6 & 77.2 & 296.0 & 116.7 & 100.0 & 5.1 & 3.0 & & 0.12 & 0.10 & 0.01 \\
\hline 1986 & 423.8 & 81.6 & 313.3 & 120.6 & 106.1 & 5.1 & 3.0 & & 0.12 & 0.11 & 0.01 \\
\hline 1987 & 462.6 & 95.5 & 345.5 & 151.3 & 112.7 & 5.0 & 3.0 & & 0.11 & 0.10 & 0.01 \\
\hline 1988 & 544.9 & 117.8 & 403.2 & 221.8 & 132.4 & 4.9 & 3.0 & & 0.11 & 0.09 & 0.01 \\
\hline 1989 & 601.5 & 136.5 & 434.6 & 182.9 & 157.9 & 4.9 & 2.9 & & 0.13 & 0.12 & 0.01 \\
\hline 1990 & 686.3 & 138.8 & 518.6 & 190.0 & 165.1 & 4.8 & 2.9 & & 0.13 & 0.11 & 0.01 \\
\hline 1991 & 708.6 & 151.9 & 523.6 & 252.8 & 168.9 & 4.7 & 2.8 & & 0.11 & 0.10 & 0.01 \\
\hline 1992 & 784.0 & 184.4 & 561.6 & 341.2 & 176.8 & 4.0 & 2.8 & & 0.12 & 0.11 & 0.01 \\
\hline 1993 & 921.6 & 194.5 & 678.5 & 324.0 & 201.0 & 4.6 & 2.9 & & 0.12 & 0.10 & 0.01 \\
\hline 1994 & 1221.0 & 263.0 & 881.9 & 394.4 & 248.0 & 4.5 & 2.9 & & 0.12 & 0.11 & 0.01 \\
\hline 1995 & 1577.7 & 353.7 & 1125.8 & 483.5 & 291.4 & 4.5 & 2.9 & & 0.13 & 0.12 & 0.01 \\
\hline 1996 & 1926.1 & 450.8 & 1362.5 & 449.8 & 314.4 & 4.4 & 2.8 & & 0.17 & 0.15 & 0.02 \\
\hline 1997 & 2090.1 & 514.6 & 1472.7 & 390.0 & 322.3 & 4.4 & 2.8 & & 0.20 & 0.18 & 0.02 \\
\hline 1998 & 2162.0 & 573.6 & 1466.0 & 609.1 & 319.1 & 4.3 & 2.8 & & 0.17 & 0.14 & 0.02 \\
\hline 1999 & 2210.3 & 630.3 & 1448.4 & 488.9 & 314.3 & 4.2 & 2.8 & & 0.21 & 0.18 & 0.03 \\
\hline 2000 & 2253.4 & 702.3 & 1427.3 & 517.8 & 314.0 & 4.2 & 2.8 & & 0.23 & 0.19 & 0.03 \\
\hline 2001 & 2366.4 & 771.9 & 1459.6 & 574.6 & 316.5 & 4.2 & 2.7 & & 0.23 & 0.19 & 0.04 \\
\hline 2002 & 2475.6 & 840.2 & 1486.5 & 628.8 & 315.2 & 4.1 & 2.8 & 0.25 & 0.23 & 0.19 & 0.04 \\
\hline 2003 & 2622.2 & 918.4 & 1541.3 & 806.0 & 320.2 & 4.1 & 2.8 & 0.30 & 0.23 & 0.17 & 0.06 \\
\hline 2004 & 2936.4 & 998.5 & 1745.8 & 822.0 & 335.6 & 4.1 & 2.8 & 0.20 & 0.24 & 0.18 & 0.06 \\
\hline 2005 & 3254.9 & 1174.5 & 1844.5 & 960.8 & 343.0 & 4.1 & 2.8 & 0.30 & 0.24 & 0.18 & 0.07 \\
\hline 2006 & 3587.0 & 1374.8 & 1931.0 & 1014.4 & 348.1 & 4.1 & 2.8 & 0.30 & 0.27 & 0.19 & 0.07 \\
\hline 2007 & 4140.4 & 1596.2 & 2193.7 & 1145.3 & 366.9 & 4.0 & 2.8 & 0.20 & 0.28 & 0.20 & 0.08 \\
\hline 2008 & 4760.6 & 1853.7 & 2435.6 & 1180.5 & 390.7 & 4.0 & 2.8 & 0.30 & 0.30 & 0.22 & 0.08 \\
\hline 2009 & 5153.2 & 2061.3 & 2526.8 & 1421.7 & 389.5 & 4.0 & 2.9 & 0.30 & 0.29 & 0.21 & 0.08 \\
\hline
\end{tabular}

1. Income data, household size and labor force data are from the China Yearbook of Rural Household Survey (2010). Income includes farm income, off-farm employment income, and other income, such as investment income and transfer payments.

2. The rural CPI data after 1985 are taken from China Statistical Yearbook (2010), and the CPIs for 1983 and 1984 are proxied by the urban CPI.

3. The off-farm wage is taken from Lu (2012).

4. We use the average number of the students older than 16. Except for the year of 2002, NBSC only reports the number with a decimal approximation. 
Table 4. Sensitivity Analysis of Total Bias for $\tau$ (the share of food costs in total costs for FAFH venues)

\begin{tabular}{|c|c|c|c|c|c|}
\hline $\boldsymbol{\tau}$ values & 0.37 & 0.2 & 0.3 & 0.4 & 0.5 \\
\hline Year & & \multicolumn{3}{|c|}{ Total Bias } \\
1983 & 0.12 & 0.12 & 0.12 & 0.12 & 0.12 \\
1984 & 0.07 & 0.07 & 0.07 & 0.07 & 0.08 \\
1985 & 0.12 & 0.11 & 0.11 & 0.12 & 0.12 \\
1986 & 0.12 & 0.11 & 0.12 & 0.12 & 0.12 \\
1987 & 0.11 & 0.11 & 0.11 & 0.12 & 0.12 \\
1988 & 0.11 & 0.10 & 0.10 & 0.11 & 0.11 \\
1989 & 0.13 & 0.12 & 0.13 & 0.13 & 0.13 \\
1990 & 0.13 & 0.12 & 0.12 & 0.13 & 0.13 \\
1991 & 0.11 & 0.11 & 0.11 & 0.11 & 0.12 \\
1992 & 0.12 & 0.11 & 0.11 & 0.12 & 0.12 \\
1993 & 0.12 & 0.11 & 0.11 & 0.12 & 0.12 \\
1994 & 0.12 & 0.12 & 0.12 & 0.13 & 0.13 \\
1995 & 0.13 & 0.13 & 0.13 & 0.13 & 0.14 \\
1996 & 0.17 & 0.16 & 0.16 & 0.17 & 0.17 \\
1997 & 0.20 & 0.20 & 0.20 & 0.21 & 0.21 \\
1998 & 0.17 & 0.16 & 0.16 & 0.17 & 0.18 \\
1999 & 0.21 & 0.20 & 0.21 & 0.22 & 0.23 \\
2000 & 0.23 & 0.21 & 0.22 & 0.23 & 0.24 \\
2001 & 0.23 & 0.21 & 0.22 & 0.23 & 0.24 \\
2002 & 0.23 & 0.21 & 0.23 & 0.24 & 0.25 \\
2003 & 0.23 & 0.20 & 0.22 & 0.23 & 0.25 \\
2004 & 0.24 & 0.21 & 0.22 & 0.24 & 0.26 \\
2005 & 0.24 & 0.21 & 0.23 & 0.25 & 0.27 \\
2006 & 0.27 & 0.23 & 0.25 & 0.27 & 0.29 \\
2007 & 0.28 & 0.24 & 0.26 & 0.29 & 0.31 \\
2008 & 0.30 & 0.26 & 0.29 & 0.31 & 0.33 \\
2009 & 0.29 & 0.25 & 0.27 & 0.29 & 0.31 \\
\hline & & & & & \\
\hline
\end{tabular}


Table 5. Per Capita Dietary Energy Consumption in Selected Countries (Kcal)

\begin{tabular}{|c|c|c|c|c|c|}
\hline & & 1990-92 & 1995-97 & $2000-02$ & $2006-08$ \\
\hline \multirow{6}{*}{$\begin{array}{l}\text { FAO (Food Balance } \\
\text { Sheet) }\end{array}$} & USA & 3510 & 3570 & 3720 & 3750 \\
\hline & Germany & 3390 & 3350 & 3480 & 3540 \\
\hline & Brazil & 2760 & 2840 & 2910 & 3120 \\
\hline & India & 2290 & 2320 & 2260 & 2360 \\
\hline & Russia & 2960 & 2870 & 2980 & 3320 \\
\hline & China & 2580 & 2840 & 2920 & 2990 \\
\hline \multicolumn{2}{|l|}{ Rural China (NBSC) } & 2485 & 2501 & 2580 & 2350 \\
\hline \multicolumn{2}{|c|}{ Rural China(After Adjustment) } & 2780 & 2920 & 3175 & 3012 \\
\hline
\end{tabular}

Sources: FAO and NBSC 